\title{
P300 in Behcet's Patients without Neurological Manifestations
}

\author{
Hulusi Kececi and Melih Akyol
}

\begin{abstract}
Objective: Behcet's disease is the association of recurrent aphthous stomatitis with genital ulceration and eye disease. Neurologic involvement patterns include meningomyelitis, a brain stem syndrome, pyramidal and extrapyramidal abnormality and stroke. In the present study, subclinical involvement was investigated by using P300 in Behcet's patients without neurological manifestation. Methods: Fifteen patients and 15 healthy volunteers were accepted for the study. P300 from vertex $(\mathrm{Cz})$ electrode sites of the 10-20 system using electrodes and motor response time were recorded. Results: Patients had significantly prolonged latencies of P300 as compared to normal controls $(\mathrm{p}=0.013)$ but no significant differences in amplitude $(\mathrm{p}=1.000)$. Patients showed a significantly delayed motor response time than controls $(\mathrm{p}=0.006)$. Nine patients $(60 \%)$ had P300 latency and eight patients $(53.3 \%)$ had motor response time values exceeding the mean of controls by two standard deviations. Conclusion: The findings suggest that the P300 measures and motor response time may reflect subclinical neurologic involvement in Behcet's disease.
\end{abstract}

RÉSUMÉ: P300 chez les patients atteints de la maladie de Behcet sans manifestations neurologiques. Objectif: La maladie de Behcet comprend une stomatite aphteuse accompagnée d'ulcérations génitales et d'une maladie oculaire. L'atteinte neurologique inclut la méningomyélite, un syndrome du tronc cérébral, des anomalies pyramidales et extrapyramidales et l'accident vasculaire cérébral. Dans cette étude, l'atteinte subclinique a été investiguée au moyen de potentiels évoqués P300 chez des patients atteints de la maladie de Behcet sans manifestations neurologiques. Méthodes: Quinze patients et 15 volontaires sains ont été recrutés pour cette étude. les potentiels évoqués P300 de sites d'électrodes au vertex du système 10-20 utilisant des électrodes et le temps de la réponse motrice ont été enregistrés. Résultats: Les patients avaient des temps de latence P300 significativement prolongés comparés aux contrôles sains $(\mathrm{p}=0.013)$, sans différence significative de l'amplitude $(\mathrm{p}=1.000)$. Les patients avaient un temps de réponse motrice significativement retardé par rapport aux contrôles ( $\mathrm{p}=0.006)$. Neuf patients (60\%) avaient une latence P300 et huit patients (53.3\%) avaient un temps de réponse motrice supérieur à deux déviations standards au-dessus de la moyenne des contrôles. Conclusion: Ces observations suggèrent que les mesures de potentiels évoqués P300 et le temps de réponse motrice pourraient refléter une atteinte neurologique subclinique dans la maladie de Behcet.

Can. J. Neurol. Sci. 2001; 28: 66-69

Behcet's disease is an uncommon, relapsing-remitting, multisystem inflammatory disorder characterized by the triad of oral ulceration, genital ulceration and uveitis. It is thought to be due to an autoimmune vasculitis involving small blood vessels. ${ }^{1}$ Involvement of the central nervous system occurs in 10 to $29 \%$ of cases, usually following systemic manifestation by months to years, but as the initial feature in $5 \%$ of patients. ${ }^{2-4}$ Behcet's disease is often a progressive disorder. Neurologic manifestations include: focal meningoencephalitis, aseptic meningitis, seizures, bulbar and pseudobulbar palsy, pyramidal tract abnormality, cerebellar ataxia, emotional incontinence, subcortical dementia, transient ischemic attacks, stroke and pseudotumor cerebri. ${ }^{1}$

Long-latency evoked potentials are referred to as cognitive evoked potentials (EP) or endogenous event-related potentials
(ERPs). The P300 is the best known of the endogenous ERPs and the generator site of the P300 is related to the neuronal activity in multiple brain regions, including inferior parietal lobule, frontal lobe, hippocampus, medial temporal lobe, along with other limbic structures. ${ }^{5}$ Event-related potentials are sometimes included as part of a battery of electrophysiologic tests used for diagnostic purposes. ${ }^{6,7}$ Abnormally prolonged P300 latencies

From the Department of Neurology (HK) and the Department of Dermatology (MA), Medical Faculty of Cumhuriyet University, Sivas, Turkey

ReCEIVEd February 14, 2000. ACCEPTED In FinAl FORM SePtember 13, 2000. Reprint requests to: Hulusi Kececi, Mehmet Pasa M. Hersek S. Guldas Apt. No:1/6 58040-Sivas, Turkey. 
have been reported in Parkinson's disease ${ }^{8}$ Alzheimer's disease and other dementias, ${ }^{9}$ multiple lacunar infarcts, ${ }^{10}$ metabolic and toxic encephalopathies, ${ }^{11}$ Huntington's disease, ${ }^{12}$ multiple sclerosis, ${ }^{13}$ human immune deficiency virus infection ${ }^{14}$ and schizophrenia. $^{15}$

Evoked potentials, including visual (VEP), brain stem auditory (BAEP) and motor (MEP), are often abnormal in patients with Behcet's disease without neurological manifestations. ${ }^{16,17}$ In addition, SPECT studies are frequently abnormal in Behcet's patients without neurological manifestations. ${ }^{18-22}$ To the best of our knowledge, the ERP test has not previously been utilized to detect subclinical involvement in Behcet's disease. The aim of the present study was to assess the utility of ERPs in patients with Behcet's disease without neurological manifestations.

\section{METHODS AND MATERIALS}

\section{Subjects}

Behcet's patients were solicited from the dermatology department. All patients met criteria established by the International Study Group for Behcet's disease. ${ }^{23}$ Control subjects, age-sex matched, were recruited from hospital staff and were healthy and without history of neurological or psychiatric diseases. All subjects were examined neurologically. Exclusion criteria included neurological or psychiatric disorders, the presence of any lesion in computerized tomography, other systemic diseases (e.g., coronary artery disease, chronic renal failure, diabetes) and use of any drugs at least in the last four weeks.

\section{P300 recording procedures}

The stimulated P300 waveforms from all patients and controls were analysed in the same fashion. P300 were recorded from the vertex $(\mathrm{Cz})$ electrode sites of the 10-20 system using electrodes affixed with electrode paste and tape referred to linked earlobes with a forehead ground and impedance at $10 \mathrm{k} \Omega$. Eye movements were monitored by an electrode placed infraorbitally. During trials in which such potentials of greater than $\pm 90 \mu \mathrm{V}$ were automatically rejected. The filter bandpass was $0.1-50 \mathrm{~Hz}$ ( $3 \mathrm{~dB}$ down, $12 \mathrm{~dB}$ octave/slope). The tone plateau duration was $100 \mathrm{~ms}$ and the rise/fall duration was $10 \mathrm{~ms}$. Prestimulus baseline was $100 \mathrm{~ms}$. Cerebral responses and motor response time were recorded by Nihon Kohden Neuropack 8 MEB 4200.

Each subject was presented with binaural tones $(85 \mathrm{~dB})$ with an interstimulus interval of $0.5 \mathrm{~Hz}$. In $80 \%$ of the trials, the tone had a pitch of $1000 \mathrm{~Hz}$ (frequent tone), and in $20 \%$ of trials it was at $2000 \mathrm{~Hz}$ (rare tone). Each subject was asked to press a button when they heard a rare tone. Tests were continued until 30 rare tones were detected by the apparatus. Amplitudes were measured from peak to peak (for N2-P3). To maintain the study blind, all records were analysed without knowing their group.

For statistical analysis, P300 latency, N2-P3 amplitude measurements and motor response times were compared via the Mann-Whitney U test.

\section{RESULTS}

Fifteen patients met the entry criteria and were accepted for the study (Table 1). The mean values of P300 latency, amplitude
Table 1: Data of patients in the study

\begin{tabular}{lll}
\hline & \multicolumn{2}{c}{ Groups } \\
Characteristics & Patients & Controls \\
$\begin{array}{l}\text { No. of Patients } \\
\text { Mean } \pm \text { SD age, y (range) }\end{array}$ & 15 & 15 \\
& $38.53 \pm 14.65$ & $38.40 \pm 14.65$ \\
$\begin{array}{l}\text { Sex, M / F } \\
\text { Mean } \pm \text { SD duration } \\
\quad \text { of disease (years) }\end{array}$ & $10 / 5$ & $(19-63)$ \\
& $10.86 \pm 9.91$ & - \\
\hline
\end{tabular}

Table 2: Latency, amplitudes and motor response time in patients and controls

\begin{tabular}{|c|c|c|c|}
\hline & Patients & Controls & Significance \\
\hline Latency (ms) & & & \\
\hline P3 & $342.13 \pm 26.80$ & $319.47 \pm 19.47$ & $\mathrm{p}=0.013$ \\
\hline Amplitude (mV) & & & \\
\hline N2-P3 & $30.57 \pm 8.98$ & $32.11 \pm 13.46$ & $\mathrm{p}=1.000$ \\
\hline $\begin{array}{l}\text { Motor Response } \\
\text { time (ms) }\end{array}$ & $401.20 \pm 61.63$ & $327.07 \pm 58.72$ & $\mathrm{p}=0.006$ \\
\hline
\end{tabular}

$P$ value from Mann-Whitney U test

and motor response time in both groups were compared (Table 2). An example is given in Figure 1. Figure 2 and Figure 3 show latency and motor response time distributions in patients and controls.

Nine patients $(60 \%)$ had P300 latency values exceeding the mean of controls by two standard deviations. Eight patients $(53.3 \%)$ had motor response time values exceeding the mean of controls by two standard deviations.

\section{Discussion}

Behcet's disease is a symptom complex of oral and genital ulceration and iritis that has a world-wide distribution but is most common in the Pacific rim and eastern Mediterranean. ${ }^{24}$ The variance in the prevalence rates of neurologic involvement in Behcet's disease was partly attributed to subspeciality practice from which different reports originated. ${ }^{25}$ In some cases without neurological signs and symptoms, there is a possibility of subclinical involvement. In SPECT studies, reduced brain blood flow has been demonstrated especially in frontal regions in those patients with and without neurological manifestations. ${ }^{18-22}$ In previous studies, abnormal BAEP, VEP and MEP values were reported in $31 \%, 25 \%$ and $28 \%$ of patients with Behcet's disease without neurological manifestation. ${ }^{16-17}$ It may be speculated that high rates of P300 latency and motor response time in our patients may be due to the fact other EP studies show only the functions of distinct anatomical pathways, whereas P300 responses are related to the neuronal activity in multiple brain regions. However, our study was not designed to determine if P300 latency and motor response time measurements are more 


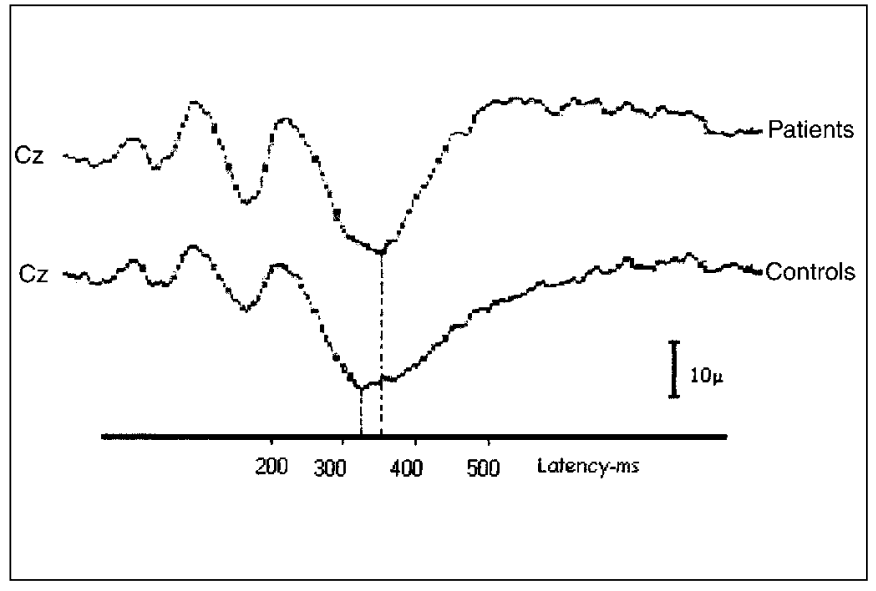

Figure 1: P300 recorded in patients and controls. Note that patients show a prolonged P300 latency as compared to controls.

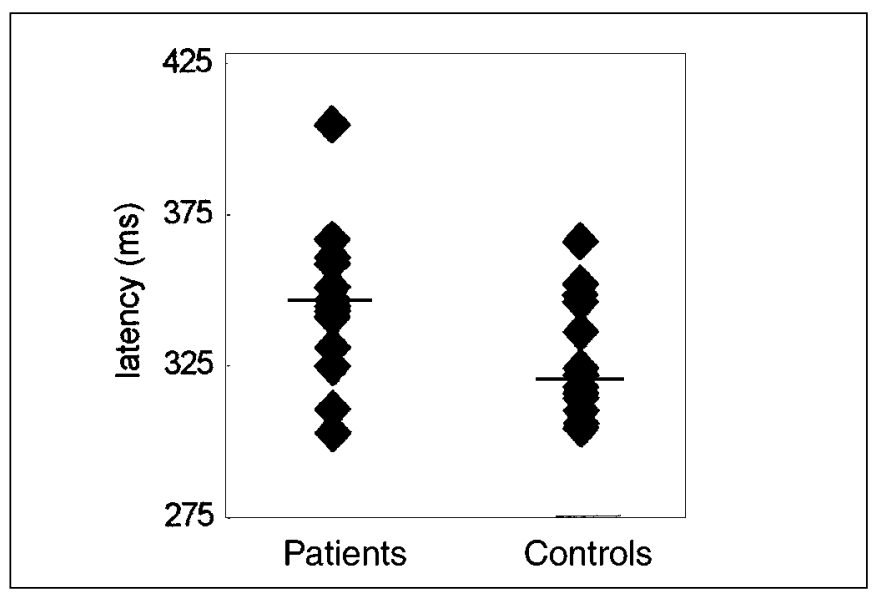

Figure 2: Latency distributions in patients and controls. Horizontal lines show mean values

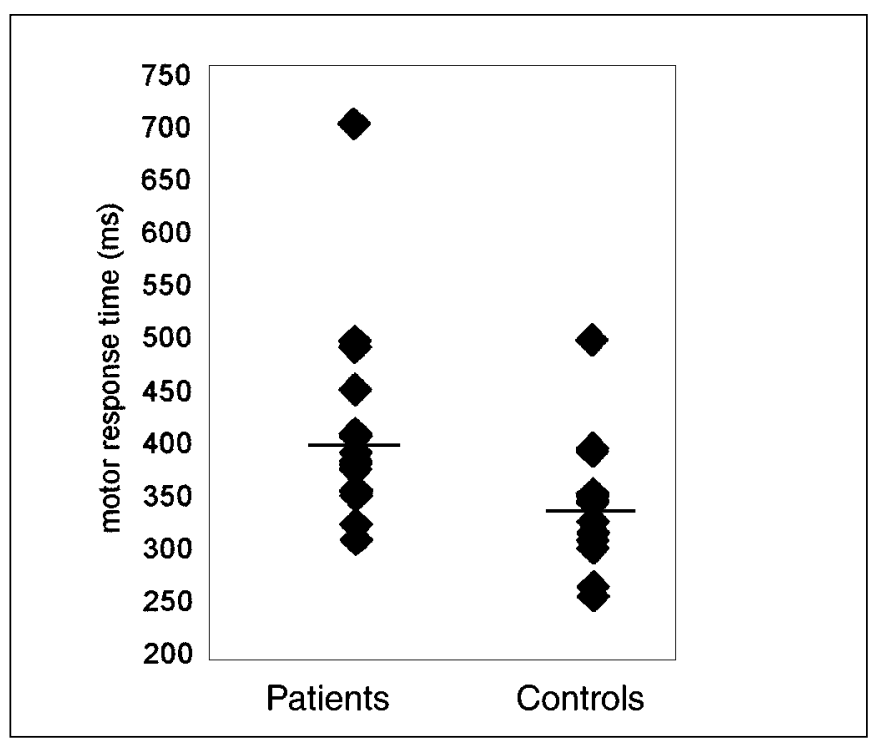

Figure 3: Motor response time distributions in patients and controls. Horizontal lines show mean values sensitive than other multimodal EP studies to detect subclinical neurophysiological dysfunction in those with Behcet's disease. Our results suggest that such a study is necessary.

In our patients without clinical signs of neurologic involvement, prolonged latencies of P300 and delayed motor response times may be related to impaired neuronal activity due to small blood vessels vasculitis. It appears that the motor responses are more abnormal than the P300s; this may result from the longer sequence of successive synaptic steps.

P300 latency and motor response time measurements may reflect subclinical neurologic involvement in Behcet's disease and may aid the early diagnosis of neuro-Behcet's disease.

\section{ACKNOWLEDGEMENT} study.

We thank Ziynet Cinar for her help with statistical analyses of this

\section{REFERENCES}

1. Nadeau SE, Watson RT. Neurologic manifestations of vasculitis and collagen vascular syndromes. In: Joynt RJ, editor. Clinical Neurology. Philadelphia: JB Lippincott Company, 1992:1-166.

2. Chajec T, Fainaro M. Behcet's disease: report of 41 cases and a review of the literature. Medicine 1975; 54:179-195.

3. O'Duffy JD, Goldstein NP. Neurologic involvement in 7 patients with Behcet's disease. Am J Med 1976; 61:170-178.

4. Chamberlain MA. Behcet's syndrome in 32 patients in Yorkshire. Ann Rheum Dis 1977; 36: 491-498.

5. Oken BS. Endogenous event-related potentials. In: Chiappa KH, ed. Evoked Potentials in Clinical Medicine. Philadelphia: JB Lippincott Company, 1997: 529-563.

6. Duffy FH, Denckla MB, Bartels PH, et al. Dyslexia: automated diagnosis by computerized classification of brain electrical activity. Ann Neurol 1980; 7: 421-428.

7. John ER, Prichep LS, Friedman J, et al. Neurometrics: computerassisted differential diagnosis of brain dysfunctions. Science 1988; 239:162-169.

8. Goodin DS, Aminoff MJ. Electrophysiological differences between demented and nondemented patients with Parkinson's disease. Ann Neurol 1987; 21:90-94.

9. Gordon E, Kraiuhin C, Harris A, et al. The differential diagnosis of dementia using P300 latency. Biol Psychiatry 1986; 21:11231132 .

10. Ito J. Somatosensory event-related potentials (ERPs) in patients with different types of dementia. J Neurol Sci 1994; 12:139-146.

11. Cohen SN, Syndulko K, Rever B, et al. Visual evoked potentials and long latency event-related potentials in chronic renal failure. Neurology 1983; 33:1219-1222.

12. Rosenberg C, Nudleman K, Starr A. Cognitive evoked potentials (P300) in early Huntington's disease. Arch Neurol 1985; 42:984987.

13. Polich J, Romine JS, Sipe JC, et al. P300 in multiple sclerosis: a preliminary report. Ind J Psychophysiol 1992; 12:155-163.

14. Goodin DS, Aminoff MJ, Chequer RS. Effect of different high-pass filters on the long latency event-related auditory evoked potentials in normal human subject and individuals infected with the human immunodeficiency virus. J Clin Neurophysiol 1992; 9: 97-104.

15. Pfefferbaum A, Wenegrad BG, Ford JM, et al. Clinical application of the P3 component of event-related potentials. II. Dementia, depression and schizophrenia. Electroencephalogr Clin Neurophysiol 1984;59:104-124.

16. Strigsby B, Bohlega S, al-Kawi MZ, et al. Evoked potential findings in Behcet's disease. Brain stem auditory, visual and somatosensory evoked potentials in 44 patients. Electroencephalogr Clin Neurophysiol 1994; 92:273-281.

17. Parisi L, Terracciano ME, Valente GO, et al. Presymptomatic 
neurogical involvement in Behcet's disease: the diagnostic role of magnetic transcranial stimulation. Electroencephalogr Clin Neurophysiol 1996; 101: 42-47.

18. Kao CH, Lan JL, Changlai SP, et al. Technetium-99m-HMPAO SPECT and MRI of brain in patients with neuro-Behcet's syndrome. Jpn J Psychiatry Neurol 1994 ;48: 77-84.

19. Arai T, Mizukami K, Sasaki M, et al. Clinicopatholgical study in a case of neuro-Behcet's disease: with special reference to MRI, SPECT and neuropathological findings. Jpn J Psychiatry Neurol 1994; 48: 77-84.

20. Trotta F, Bajocchi G, Colamussi P, et al. Cerebral hypoperfusion detected by SPECT in early neuro-Behcet's syndrome. Nucl Med
Commun 1998; 19: 777-780.

21. Garcia-Burillo A, Castell J, Fraile M, et al. Technetium-99 mHMPAO brain SPECT in Behcet's disease. J Nucl Med 1988; 39: 950-954.

22. Avci O, Kutluay E, Argon M, et al. Subclinical cerebral involvement in Behcet's disease: a SPECT study. Eur J Neurol 1998; 5: 49-53.

23. Criteria for diagnosis of Behcet's disease. International Study Group for Behcet's Disease. Lancet 1990; 5: 1078-1080.

24. O'Duffy JD. Behcet's syndrome. New Eng J Med 1990; 322: 326328.

25. Serdaroglu P, Yazici H, Ozdemir C, et al. Neurologic involvement in Behcet's syndrome. Arch Neurol 1989; 46: 265-269. 